\title{
ARCAÍSMO NA TRAGÉDIA Reconciliações religiosas na Oréstia de Ésquilo
}

\author{
Jorge Ferro Piqué*
}

Durs coisas existem nas quais tudo ć claro e luminoso a monlanha dos animais e a montanha dos deuses. Entre as duas se cstende o vale crepuscular dos homens.

Paul Klce, Diảrio (1903).

eitores modernos freqüentemente sentem uma sensação de estranhamento frente ao desenrolar das tragédias gregas. Parecemos estar fora de seu quadro de referência. Isso se deve, sem dúvida, a que possuimos concepções religiosas, juridicas $\mathrm{c}$ políticas muitas vezes tão diferentes que nos impossibilitam penctrar no cerme dos acontecimentos trágicos.

Para precaver-nos contra uma projeção de nossa mentalidade moderna sobre o homem grego antigo, ${ }^{\prime}$ acreditamos que seria útil uma comparaçāo da tragédia grega com concepçōes religiosas de povos primitivos, a qual poderia

* Universidade Federal do Parani.

1 VERNANT. J.-P.Esboços da Vonlade na Tragédia Grega. In: . VIDAL-NAQUET, P. Mito e Tragédia na Grécia Amriga. São Paulo: Duas Cidades, 1977.p.43. 
nos ajudar a compreender melhor que tipo de manifestação religiosa ali se desvela e a razão de sua "lógica”, sem, no entanto, esgotá-la.

Quando se inicia a Oréstia, ć nos apresentada uma Argos envolta em trevas noturnas, na ansiosa espera de um sinal luminoso que a livraria deste "inverno", desta "noite" em que se encontra. O sinal da fogueira, que partira do longínquo Monte Ida, acabará se revelando, no entanto, indice de una vitória enganosa, como nos é mostrado na primeira peça da trilogia, Agamêmnon.

$\mathrm{Na}$ verdade, como veremos a seguir, é a própria trilogia, enquanto nova reconciliação política e religiosa, que terá essa função de um sema (sinal) benćfico para a cidade, que não é Argos, mas sim a própria Atenas. Entretanto, até cliegarmos à luminosa procissão, que acompanhará as Erínias até suas novas honras, teremos ainda um longo caminho.

A Oréstia de Ésquilo, apresentada em 458 a.C., portanto, dois anos antes da morte de seu autor, foi a única trilogia completa que chegou até nós. Era composta por três tragédias: Agamêmmon, As Coéforcus c As Eumênildes. ${ }^{2}$ Sua matéria-prima foi recollida nas histórias dos regressos dos heróis, que foram lutar contra a cidade sagrada de Tróia. Nela vemos o desenrolar de uma série de crimes de sangue que atinge a casa real de Argos.

Em Agamếmnon, após a queda de Tróia, o comandante aqueu é recebido como herói por sua esposa, Clitemnestra, que a seguir o assassina junto com a escrava troiana Cassandra. O crime teria como motivo mais imediato o sacrificio, anos antes, de Ifigênia, filha do casal, para que a esquadra grega oblivesse ventos favoráveis que a levassem a Tróia.

Nas Coéforas, Orestes, diante do túmulo do pai assassinado pela própria esposa, encontra a irmã, Electra, e ambos, invocando o espirito do morto, decidem a morte da mãe. Orestes viera do exilio, depois de receber do Oráculo de A polo a missão de vingar o pai, caso contrário, pagaria com a própria vida a omissão, depois de terriveis sofrimentos. Após matar Clitemnestra e seu amante, Egisto, Orestes se dirigc ao santuário de Apolo cm Delfos, para aplacar a maldição que nasee do sangue derramado da mãe. No linal da peça surgem, em sua perseguição, as Erínias (“Fúrias"), antigas divindades de formas monstruosas, cuja funçīo cra vingar crimes entre consangüíneos.

A terceira peça, As Eumênides, inicia-se com Orestes no Templo de Apolo, cm Delfos, mas já alcançado pelas Erínias, que exigem a entrega do matricida. O deus o manda então a Atenas, onde a deusa Palas Atena julgará o direjto das duas partes. Para isso, Atena institui cm cena o Areópago, o principal tribunal da cidade, que julgava crimes sangrentos. Durante o julgamento, Apolo

2 O drama satírico que completava a tetralogia, Protelt, está atualmente perdido. 
se apresenta como testemunha e se diz o maior responsável pelo crime contra Clitemnestra. Sua ação é na verdade a manisfestação da vontade de seu pai,Zeus, que desejava vingar, assim, a morte inglória de um herói detentor do cetro real. Com o voto, a favor, de Atena, Orestes é absolvido. Em vista desse resultado, as Erínias ameaçam o solo ateniense com a esterilidade, mas Atena lhes diz que scrão bem-vindas e cultuadas na cidade se accitarem a decisão que, em última instância, procede do próprio Zeus. A trilogia termina com a transformaçāo das Erínias em entidades protetoras de Atenas, as Eumênides, isto é, as "Benfazejas".

Examinando alguns aspectos do material que foi trabalhado por Ésquilo, podemos reconhecer a evidente presença de elementos arcaicos na Oréstia. Uma das concepções religiosas arcaicas estudadas por diversos antropólogos e de grande difusão em várias culturas é a noção de mana, nome sob o qual se manifesta na Melanésia, onde foi mais detalhadamente investigada. É difícil definir uma noção simultaneamente tão concreta e tão abstrata, estudada desde o início deste século pelas correntes antropológicas francesas.

Marcel Mauss afirmava que -o mana é uma força, e $\mathrm{cm}$ especial a dos seres espirituais, isto é, a das almas dos antepassados e dos espíritos da natureza". ${ }^{3}$ Mas também, acrescenta, é tudo o que se relaciona com isso: "poder de bruxo, qualidade mágica de uma coisa, coisa mágica, ser mágico, ter poder mágico, estar encantado, atuar magicamente".4 O que, portanto, o caracteriza é uma fusão primitiva entre o ritual, o individuo agente, as pessoas e as coisas; "é a força por excelência, a autêntica eficácia entre as coisas que corrobora sua ação mecânica sem aniquilá-la". Está relacionado, como jả foi mencionado, às almas dos mortos, mas o simples animismo não o explica, pois apenas os "tíndalos", isto é, os espíritos eficazes, as almas dos chefes, de tribo ou de família, são capazes de, num ritual, invocados por indivíduos qualificados, desencadeá-lo.

Mauss fala ainda de outras duas características do mana: "É transmissivel e contagioso por natureza" ${ }^{\prime 6}$ "É suscetivel de especializar-se, hả mana que enriquece e há mana que mata".?

Como poderemos ver, a partir dessa noção mágica, impessoal, que se expressa nos homens e nas coisas, mas que os transcende, podemos estabelecer uma relação com certas interpretações não casualmente francesas, de que as personagens trágicas são arrastadas por força de um antigo crime. Onde,

3 MAUSS, Marcel. Esbozo de uma Teoria General de la Magia. In: . Sociologia y Amropologia. Madrid : Editorial Tecnos, 1971. p. 123.

4 Ibid., p. 123.

5 Ibid., p. 125.

6 lbid., p. 130.

7 Ibid., p. 131. 
conforme Rivier, citado por J.-P. Vernant, ${ }^{8}$ forças supra-humanas tomam na verdade as decisões, coagindo o indivíduo em uma única e inevitável direção, ou conforme um enfoque mais atenuado do próprio Vernant, seguindo Gernet: "não é o indivíduo como tal que é o fator do delito. $O$ delito existe fora dele, o delito é objetivo"'. ' É a essa especialização maléfica do mana que este autor parece identificar a palavra daimon, enquanto "numen sinistro que se manifesta sob múltiplas formas, em momentos diferentes, na alma do homem e fora dele". 10

Em uma sociedade onde toda "força" e todo o "valor" estão dentro do âmbito do mana, realmente a responsabilidade pelo crime, ou a suposta vontade do criminoso, não são relevantes no que tange a sua punição, já que os crimes antigos, o criminoso e o que seriam suas motivações psicológicas, além do crime atual (até), da contaminação (miasma) e do castigo, são todos aspectos englobados por uma força semipessoal na tragédia, a ananke (o Destino), o daimon ou alaston (o Espírito Vingador), as Erínias, que não são identifícáveis, como o mana, a um ser, a uma ação ou a uma qualidade, e que se constitui no motor de muitos acontecimentos dramáticos.

Além dessas aproximaçōes, toda a "lógica" da expansão dos malefícios é, como no caso do mana, a da contaminação, seja pela linhagem, já que descendentes são atingidos, seja pelo espaço, já que toda a comunidade, Tróia ou Argos, é envolvida.

Assim, podemos ver quanto Ésquilo teve que ceder a esta noção tão difundida e ainda presente na sociedade de sua época, que recebeu na Melanésia o nome de mana, mas entre os iroqueses é orenda, c para os algonquinos, manitu: o poder, mais precisamente, o poder místico.

Mas, como dissemos, essa força mágica é passível de especialização. Há vários tipos, benéficos e maléficos. Uma especialização característica é encontrada nas sociedades de caçadores-coletores. Um dado fundamental para compreendermos a importância dos comportamentos religiosos especificos das culturas dos caçadores é que, por aproximadamente dois milhões de anos, ou mais, como sugerem algumas descobertas mais recentes, os palcantropídeos viveram da caça e em menor escala da colcta. ${ }^{11}$ Segundo Mircea Eliade "a

8 VERNANT, J.-P. Op. cit. , p. 44-5

9 Ibid., p. 55

10 VERNANT, J.-P. Tensões e Ambigüidades na Tragédia Grega. In: .VERNANT, J.-P:___.VIDAL-NAQUET, P. Mito e Tragédia na Grécia Antiga. São Paulo: Duas Cidades, 1977. p. 27.

11 Embora alguns autores nāo concordem com uma tal profundidade temporal da caça, sem dúvida o contato com o corpo do animal morto e a alimentação com sua carne remonta aos australopitecídeos. 
incessante perseguição e sacrificio da caça acabaram por criar um sistema de relações sui generis entre o caçador e os animais chacinados (...) a 'solidariedade mística' entre o caçador e suas vitimas é revelada pelo próprio ato de matar; o sangue derramado é, em todos os pontos, semelhante ao sangue humano". ${ }^{12}$

Se examinarmos comparativamente certas concepções de povos caçadores, como os esquimós, por exemplo, destaca-se a noção de que o ato de matar um animal desencadeia automaticamente uma resposta contrária. Como no caso do mana, onde os espíritos humanos e animais têm uma grande importância, aqui a alma do animal abatido, se não for apaziguada, procurará uma vingança contra o caçador.

Em muitos povos, esse estreito laço entre caçador e caça vai além do demonismo e ganha uma personificação na figura de um Senhor ou Senhora das Feras, que zela para que o caçador mate só aquilo que necessita para sua alimentação, e que defende também os animais caçados, isto é, regula e equilibra este tipo de relação.

Se é verdade que a sociedade de caçadores paleolíticos iniciaram sua penetração $\mathrm{em}$ regiōes marginais ou de dificil acesso por volta do décimo milênio a.C., enquanto um pouco depois já são detectados aldeamentos neoliticos no sudoeste asiático, com agricultura e depois cerâmica; ${ }^{13}$ isto de forma alguma significou o desaparecimento deste tipo de espiritualidade especifica ao caçador: "os guerreiros, os conquistadores e as aristocracias militares prolongam o simbolismo e a ideologia do caçador típico", ${ }^{14}$ tanto nas confrarias militares das tribos indo-européias quanto nas tribos turco-mongóis.

Encontraremos também traços desta ideologia em certas divindades cultuadas na Grécia, embora já desde 6000 a.C., aproximadamente, encontremos em solo grego o inicio do Neolítico. A antiga Senhora das Feras da pré-história é retomada em Ártemis, a potnia theron, a um só tempo padroeira dos caçadores, dos animais ferozes $\mathrm{c}$ das virgens. Mas aqui Ártemis, após milhares de anos de civilização agrícola, já se mostra como um produto sincrético, apresentando também os atributos e os prestigios de uma deusa Terra-Mãe, protetora das crias. No seu mais antigo local de culto, a Arcádia, cla esteve associada a Deméter e a Perséfone.

Eliade nos informa que "Heródoto (II, 156) escrevera que Ésquilo considerava Ártemis como a fillha de Deméter", 15 um dos aspectos de uma deusa ctônica.

12 ELIADE, M. Histórias das Crenças e das Idéias Religiosas. Tomo I, v. 1, Rio de Janciro: Zahar, 1978, p. 21.

13 CLARK, G. A Pré-História. Rio de Janciro: Zahar Ed., 1975. p. 78-80.

14 Ibicl., p.55. 
Adiciona-se, portanto, também, além da ideologia dos caçadores na integração espiritual efetuada na Grécia, este traço profundamente poderoso da religiosidade agrícola: on a pur établir que, dans un fond de religion populaire singulièrement persistent, l'idée de la Terre-Mère est restée l'elément principal". ${ }^{16}$ Assim, é que Ártemis enquanto Senhora das Feras e associada à religiosidade popular, fiel à Terra-Mãe e seu poderes simultaneamente subterrâneos e prolíficos, exige o sacrificio da virgem, Ifigênia, filha do caçador real, Agamêmnon, movimentando novamente a corrente de crimes, entre os quais, o que levará este rei à morte.

O sacríficio exigido por Ártemis, por outro lado, não impedirá que se cumpra a Justiça de Zeus contra Páris e sua comunidade, mas vincula, irremediavelmente, a vitória grega sobre os troianos aos antigos crimes da casa real dos Atridas. A morte de Agamêmnon é de fato, o nó que une na tragédia, todos esses acontecimentos presentes, passados e mesmo futuros.

O que temos na Oréstia é o contato, simultaneamente, convergente e conflituoso entre esse amálgama de vários tipos de arcaísmos e a religiosidade, especificamente, esquilea baseada no poder e na Justiça de Zeus, o que de fato, não é apenas um problema religioso, mas também jurídico e político.

Figuras miticas mais arcaicas como: Terra, Têmis, Ártemis e as Erínias, não podem ser apenas eliminadas pela presença toda poderosa de Zeus, o novo pai de deuses e homens. Conforme nos dizem Genet e Boulanger: “Eschyle n'aurait pu dresser l'image terrifiant de ses Furies si (...) n'auraint maintenu toute leur puissance sur les âmes dans le moment où la cité imposait sa juridiction. Par lì encore beaucoup d'archaïque s'est conservé dans la pensée religieuse". 17

Assim, a morte de Agamêmnon é necessária do ponto de vista cego, imediato e mecânico da maldição, que existe e não é negado. ${ }^{18}$ Mas, do ponto de vista da religiosidade esquílea, é apenas um momento no caminho que conduz até a confirmação do poder de Zeus. A morte de Clitemnestra, por sua vez, já não é uma morte onde atuam as forças vingadoras das Erínias, ${ }^{19}$ mas sim a ordem

15 ELIADE, M. Op. cit., v.2, p. 112.

16 GERNET, L; BOULANGER, A. Le Génie Grec dans la Religion. Paris: La Renaissance du Livre, 1932. p. 57.

17 lbid., p. 162. v. 521-2).

18 "E lei que o sangue, uma vez derramado em plena Terra, exija sangue novo"(Coéforas,

19 Apesar destas terem sido invocadas por Orestes nas Coéforas, nas Eumênides ele as reprova por não terem perseguido sua mãe. As Erinias defendem-se sustentando que ao matar o marido Clitemnestra não cometera um crime contra seu próprio sangue, como é o caso de Orestes (Eumênides, v.277). 
do Oráculo de Apolo, porta-voz de Zeus. Esse agon (combate) entre Orestes e Clitemnestra, entre o filho do rei e sua mãe, é, no plano humano, o reflexo do enfrentamento entre Zeus $\mathrm{e}$ as Erínias. Mas enquanto nas Eumenides as Erínias são levadas à cena em pessoa, uma vez que perseguem Orestes, não mais se utilizando de intermediários que capturam suas vítimas em armadilhas; Zeus é representado por dois filhos, Apolo e Atena, ambos sendo, em última instância, a confírmação do poder do pai. ${ }^{20}$

Esta resistência às concepções mais arcaicas, dentro do ambiente da polis no século $\mathrm{V}$ a.C., pode ser observado pelo tipo de morte que os indivíduos atingidos pela contaminação apresentam. Numa sociedade em que a noção de maldição, enquanto mana maléfico, é soberana, o amaldiçoado "se deixa morrer". Lévi-Strauss sintetizou muito bem este conjunto de mecanismos sociopsicofisiológicos:

(...) um indivíduo, consiste de ser objeto de um malefício, é intimamente persuadido pelas mais solenes tradições de seu grupo, de que está condenado; parentes $\mathrm{c}$ amigos partilham desta certeza. Desde então a comunidade se retrai: afasta-se do maldito, conduz-se a seu respeito como se fosse, não apenas já morto, mas fonte de perigo para o seu círculo; em cada ocasião e por todas as suas condutas, o corpo social sugere a sua morte à sua infeliz vítima, que nāo pretende escapar àquilo que ela considera seu destino inelutável (sem grifo no original). Logo, aliás, celebram-se por ela os ritos sagrados que a conduzirão ao reino das sombras. Incontinenti, brutalmente privado de todos os seus elos familiares e sociais, excluído de todas as suas funções e atividades pelas quais o individuo tomava consciência de si mesmo, depois encontrando essas forças tão superiores novamente conjuradas, mas somente para bani-lo do mundo dos vivos, o enfeitiçado cede à ação combinada do intenso terror que experimenta, da retirada súbita e total dos múltiplos sistemas de referência fornecidos pela conivência do grupo, enfim, à sua inversão decisiva que, de vivo, sujeito de obrigaçōes, o proclama morto, objeto de temores, de ritos e proibições. A integridade física não resiste à dissolução da personalidade social. ${ }^{21}$

20 Zeus não tem uma só fala nas tragédias de Ésquilo, que chegaram até nós. Esse "silêncio" contrasta, paradoxalmente com as inúmeras referèncias a ele. Assim, atrás do antagonismo Apolo/Atena vs. Erínias esconde-se outro mais fundamental entre seus genitores divinos: Zeus vs. Noite, uma antiga deusa, filha de um deus primordial, Caos.

21 LEVI-STRAUSS, C. O Feiticeiro e sua Magia. In: Antropologia Estrutural. Rio de Janeiro: Tempo Brasileiro, 1975. p. 193-4. 
A queda da pressão sangüínea acaba levando o individuo a um estado de choque e por fim à morte. Podemos ver nas Coéforas que a punição de Orestes, caso não se submeta às ordens de Apolo, apresenta semelhanças com o acima descrito:

(...) ninguém jamais o acolherá nem lhe ofereceria o leito; finalmente desprezado por todos, sem um só amigo tal criatura morreria na miséria de um mal que a aniquilaria sem remédio (Coefforas, v.390-394).

Essa eficácia da maldição, observada por exemplo, nas práticas de voodoo ou entre os aborigines australianos, no entanto, não é reproduzida fielmente na Oréstia por Ésquilo. Ao contrário, o indivíduo sentindo-se ameaçado reage fortemente. Clitemnestra ao ouvir o coro mencionar a maldição do povo argivo sobre ela (v. 1634-5), nega a autoria do crime, que antes fora obra sua e justificável, e o atribui ao demônio que habita a casa (v. 1745). Nenhum dos atingidos pelos crimes, Ifigênia, Agamêmnon e Clitemnestra, simplesmente se deixa morrer. Ou são mortos através da astúcia, do ardil, da armadilha; ou fogem e são perseguidos, como no caso de Orestes. Se tanto Clitemnestra quanto Orestes, os únicos que podem, procuram fugir à responsabilidade dos crimes cometidos, argumentando que divindades os impulsionaram a essas ações, é porque o nexo entre individuo e seus atos, entre responsabilidade e punição, já estava instaurado na cidade, e é escapando a ele que procuram salvar-se.

Podemos observar assim, um contraste entre dois comportamentos do herói trágico, que é na verdade a manifestação da tensão entre uma concepção mítica e uma concepcooes política: cede e deseja o seu papel de vingador, instrumento de forças sinistras, aliando ethos (caráter) e daimon, mas espera escapar a essas mesmas forças proclamando-se isento de responsabilidade. Como conseqüência, o jogo da tragédia é jogado simultaneamente em dois tabuleiros, movendo-se constantemente de um sentido para outro, sem nunca excluir um deles integralmente.

Assim, durante grande parte da trilogia, jả encontramos uma ideologia que não está totalmente presa à noção primitiva de mana, enquanto uma força cega destrutiva, com uma expansão puramente mecânica por contaminação. $O$ processo crime-punição já não está totalmente interiorizado no indivíduo, como o encontramos em várias sociedades; da sociedade surge um instrumento externo ao criminoso, o Vingador, que já é o primeiro passo em direção ao Direito, enquanto instância independente do indivíduo. A criação de um tribunal 
por Atena e a absolvição de Orestes realiza de fato esta nova ordem religiosajurídica, que tem seus limites decretados pelo poder deste Deus Celeste, que se sobrepõe e ao mesmo tempo integra os poderes mágicos subterrâneos.

Se por um lado, essa experiência fundamental do caráter sagrado do Céu e dos fenômenos celestes e atmosféricos, onde se revelam espontaneamente a transcendência e a majestade, parece atingir tão fortemente a sensibilidade religiosa de Ésquilo; por outro lado, ele não poderia esquecer as "igualmente importantes e significativas (...) 'revelaçōes' da noite e das trevas, do sacrificio do animal caçado e da morte de um membro da família, das catástrofes cósmicas, das eventuais crises de entusiasmo, de loucura ou de ferocidade homicida dos membros da tribo". 22

Ao representar dramaticamente a transição para uma nova ordem política, jurídica e religiosa que é a polis, onde elementos como crimes de sangue são percebidos como uma ameaça fortíssima aos laços que deviam unir cidadãos dentro da cidade; Ésquilo toma como modelo mítico a perseguição de uma fera selvagem, modelo este que foi amplamente utilizado como símbolo da conquista de um território e da fundação de um Estado pelas sociedades tribais. Mas aqui, na Oréstia, é da caça por fím frustada de um ser humano por divindades com traços animalescos, que emerge a Cidade e suas instituições, seus tribunais e sua tão desejada pacificação interna.

Dessa forma, particularmente, a linhagem sobrevive, não só pela libertação de Orestes, mas também por Menclau, a outra águia junto com Agamèmnon, que provavelmente é retomado em suas aventuras na ilha de Faros, no drama satírico Proteu, que fechava a tetralogia, abrindo aos espectadores um horizonte futuro tranqüilizador, onde o mal não nascerá de um bem.

Embora, tendo consciência das múltiplas possibilidades interpretativas que a trilogia esquilea nos oferece, concluímos, portanto, parcialmente, que a habilidade de Ésquilo está em discutir através das lendas heróicas, que constituiam o ciclo troiano a atual situação da cidade de Atenas, mas sem negar a tradição que é sua matéria-prima, contrastando e harmonizando novos e velhos deuses, religiosidade popular e piedade a Zeus, a força da Mãe e o império do Pai, maldições e tribunais, em um todo em que finalmente a Dike (Justiça) do Pai vence outra Dike, mais primitiva, mas que nunca será totalmente excluída, onde a philia (laço) civil não desconhece o Terror e onde o sofrimento, por fim, conduz a sabedoria (Agamêmnon, v. 212).

22 ELIADE, M. História das Crenças e das Idéias Religiosas, Tomo I, v. I. Rio de Janeiro: Zahar, 1978. p. 46. 


\section{RESUMO}

Neste artigo tentamos demonstrar a relação entre várias características da tragédia de Ésquilo, como aparecem na Oréstia, e o conceito de mana, que foi investigado pela Antropologia em culturas primitivas. Nossa conclusão é que Ésquilo teve que reconciliar conceitos religiosos arcaicos, que existiam na polis, com sua crença principal, a Justiça de Zeus.

Palavras-chave: Literatura Grega, Tragédia, Ésquilo.

\section{ABSTRACT}

In this paper we try to demonstrate the relationship between several features of the tragedy of Aeschylus, as they occur in the Oresteia, and the concept of mana, which was investigated by anthropologists in primitive cultures. Our conclusion is that Aeschylus had to reconcile arcaic religious concepts, that remained in the polis, with his main belief, the Justice of Zeus.

\section{REFERÊNCIAS BIBLIOGRÁFICAS}

CLARK, G. A Pré-História. Rio de Janeiro: Zahar, 1975. 287 p.

ELIADE, M. História das Crenças e das Idéias Religiosas, Tomo I, v. 1 e 2 . Rio de Janeiro: Zahar, 1978. $284 \mathrm{p}$.

ESQUILO. Agamêmnon. Les Choéphores. Les Euménides. Texte établi et traduit par Paul Mazon. Paris: Les Belles Lettres, 1952.

. Oréstia: Agamêmnon, Coéforas, Eumênides. Tradução do grego, introdução e notas por Mário da Gama Kury. Rio de Janeiro: Zahar, 1991. 194 p.

GERNET, L; BOULANGER, A. Le Génie Grec dans la Religion. Paris: La Renaissance du Livre, 1932. $327 \mathrm{p}$.

LÉVI-STRAUSS, C. O Feiticeiro e sua Magia. In: Antropologia Estrutural. Rio de Janeiro: Tempo Brasileiro, 1975, p. 193-214,

MAUSS, M. Esbozo de una Teoria General de la Magia. In: Sociología y Antropología. Madrid: Editorial Tecnos, 1971. p. 45-152.

VERNANT, J.-P. ; Tensões e Ambigüidades na Tragédia Grega. In: VERNANT, J.-P; VIDAL-NAQUET, P. Mito e Tragédia na Grécia Antiga São Paulo: Duas Cidades, 1977. p. 19-40. 

. Esboços da Vontade na Tragédia Grega. In: ; . Mito e Tragédia na Grécia Antiga. São Paulo: Duas Cidades, 1977. p. 41-76. 